\title{
Determinants of Human Resource Productivity in Iran
}

\author{
${ }^{1}$ Mokhtari Mehran*, ${ }^{2}$ Motiee Reza \\ ${ }^{1}$ Department of management, Chaloos Branch, Islamic Azad University, Chaloos, Iran \\ ${ }^{2}$ Department of management, Babol Branch, Islamic Azad University, Babol, Iran \\ *rm.search2011@gmail.com
}

\begin{abstract}
According to the modern growth theory, the accumulation of human capital is an important contributor to economic growth. Investment in human resources and educating and training human force to learn different skills to advance the production process can improve the production quality and leads to efficient use of material capital and optimum utilization of them through improving the skill and proficiency of the workforce, making them efficient and increasing capabilities. The results of the studies on the role of Human resources in economic growth from 1966 up to now show that the better utilization of workforce, effective utilization of capitals and physical equipments, using the best skilled expert workforce, utilization of advanced equipments and machinery with advanced technologies and the proficiency of more efficient and desired resources of production factors improves the economic growth of Iran. This research show that Iran's economy, with 6\% growth potential, hopes for improving the skill of human resources, labors and experts to change the current economic growth rate of $4.5 \%$ to over $8 \%$.
\end{abstract}

Keywords: Human Resources Productivity, economic growth, co-integration, Development

\section{Introduction}

The analysis of workforce mechanism as an important factor in economic planning is given great attention to in economic growth. Human resources are the most valuable property of a country. Human has potential because of his genetic endowment, which leads unlimited material and spiritual productions and achievements whenever they are used. Japan, which is deprived of many natural resources for economic prosperity, has the second strongest economy through developing and flourishing its human resources and brought comfort to many people in the world with the blessings of its people's intellectual products. Human capital is one of the three main factors in every economic activity besides the other two factors i.e. money and social capital. Human capital which means talented, motivated, and creative workforce has somehow priority over money capital because money capital will be wasted if there is no human capital. Equipments will be at human resources' disposal and if this force does not have enough motivation to improve them, he will not improve them but will even waste them. Intense competition in today's world calls economic firms' attention to efficiency enhancement, final goods and services price reduction and quality improvement and only those economic competitors who can improve their efficiency consistently will be able to compete. Dependence on human resources development is an important factor in improving the efficiency of economic firms, which can be effective in using new technologies and in producing and supplying competitive goods and services with higher quality. Human force plays a significant role in increasing production level and optimum utilization of resources. According to present indices, development evaluation of a country depends on the role of human resources capital in creating value added. Statistical surveys show that the role of human force in GNP is more than 70 percents while this index is different in various economic sections of Iran i.e. about 20 percent.

Human Resource Productivity: According to the Japan Productivity center (JPC) definition, productivity is a priority and a national choice. Every effort to increase productivity leads to the increasing of social welfare. In general, productivity refers to the relationship between what you put in to a business (inputs) and the final result (output). However, in terms of human resources, productivity is more difficult to measure, understand and define. What influences the productivity levels of your staff is wide variety of skills, characteristics and attitudes. This includes formal training and qualifications, motivation levels, initiative, team skills, attention to detail, judgment, multi-task abilities, communication skills, general attitudes and work ethos. You may employ someone who has considerable training in the skills you are looking for, but later they may lack motivation or attention to detail which can have a negative impact on the productivity of your firm as a whole. In addition, if your highly motivated staff members lack judgment and initiative qualities, your business organizational culture will be considerably weakened at 
any time when you are not directly supervising activities. This is why it is important for you to not only identify suitable skills in potential staff members, but also to develop and foster these skills in the workplace on a continual basis. Establishing a clear organizational culture and approach to business will have an impact on staff attitudes and motivation and is a good way of maintaining a consistent standard.

One of the reasons for the renewed interest in organizational change by labor economists was the attempt to understand why technology seemed to increase the demand for human capital, and thus contribute to the rise in wage inequality experiences by the US, UK and other countries since the late 1970s. Many theories have been proposed (see Autor et al. 2003), but one hypothesis is that lower IT prices increased decentralization incentives for the reasons outlined in Garicano's (2000) model discussed above. Further, decentralization could be complementary with skills because more educated workers are better able to analyze and synthesize new pieces of knowledge so that the benefits of the local processing of information are enhanced. Second, the cost of training them for multi-tasking is lower and they are more autonomous and less likely to make mistakes.

This has three main implications: (i) Decentralization lead to skill upgrading within firms. This is due to the fact that the return to new work practices is greater when the skill level of the workforce is higher; (ii) a lower price of skilled labor relative to unskilled labor will accelerate the introduction of organizational changes associated with decentralization; (iii) Skill intensive firms will experience greater productivity growth when decentralizing. Van Reenen and Caroli (2001) find support for all three predictions. They estimate production functions (with the relevant interactions), skill share equations and organizational design equations. A novel feature of this approach is that because labor is traded in a market, it is possible to use local skill price variation to examine the complementarily issues. They find that higher skill prices make decentralization less likely, consistent with "skill biased organizational change"1.

Human Resource in Development: Selden and Colvin (2003) stated that 70 - 80\% of acquisitions fail, meaning that they create no wealth for the share owners of the acquiring company. Successfully integrating the target and the acquirer's businesses after the transaction closes is critical to achieving the goal of the combination, which is, making the new entity worth more than the sum of its parts. One of the ways to accomplish this is to effectively implement the required changes and address the related dynamics occurring in the new entity. Most mergers and acquisitions deals fail to accomplish many of the strategic objectives so optimistically projected in the initial announcements. Schmidt (2003) has identified five major roadblocks to merger and acquisition (M\& A) success, the last three of which are HR issues: Inability to sustain financial performance (64\%), loss of productivity (62\%), incompatible cultures (56\%), loss of key talent (53\%), and clash of management styles (53\%). According to Marks (1997), human resource professionals should take an active role in educating senior executives about HR issues that can interfere with the success of the merger and with meeting key business objectives. His work has stated the important role of HCD to smoothen the transition.

According to statistics of UNDP (United Nations Development Plan), the role of human resources in national capital is $80 \%$ in Japan, 78\% in Germany and Spain and 72\% in Turkey. National development is a comprehensive process and concerns the improvement of all life aspects of a nation. In addition to improving production and income conditions development brings about fundamental changes in institutional, social and official structures and also in general attitudes of people and even includes people's customs, traditions and beliefs in some cases. In recent decades, special attention was paid to human resources as a smart factor, which plays a key role in systems with its skill and innovation. Efficient human resources are counted as the utmost important capital of a country. Basically, knowledge capital is more valuable than production capital. In fact, smart human resources are the main engines of success. Leading organizations are seeking to use minds worldwide and try to find and select the most talented ones as the pivot in the business area of firms. Therefore, we should regard human resources as the pivot of development to reach stable development and should make the largest investments on human resources as it was done by some Third World countries like South Korea, China and Malaysia to reach development in the new wave. There is a need to develop human resources in the fields of export marketing, quality control and general skill enhancement. This will enhance the productivity and quality

${ }^{1}$ Bloom, Sadun and Van Reenen (2009) also find robust empirical evidence that firms with more skilled employees are more decentralized. 
improving competitiveness of exports. There is also a need to train people in international fashion to keep in touch with the ever-changing trend and to cater to the clothing needs of the developed nations.

Human Resources Skill in Economic Growth: An educated and skilled human resource is a key lever for accelerating economic growth and human development, says Deputy President Kgalema Motlanthe. "By enhancing the skills, the knowledge and the abilities of individuals, Human Resource Development serves to improve the productivity of people in their areas of work, whether in formal or informal settings," Motlanthe said during the National Skills Summit in Pretoria. He explained that the county's current Human Resource Development Strategy (HRDS) was designed to complement a range of purposeful development interventions. "It is a coordination framework intended to combine the key levers of the constituent parts of the Human Resource Development system into a coherent strategy." The strategy aims to bring about articulation between subsystems to allow for optimal achievement of systemic outcomes, facilitate holistic analyses of education and training and the functioning of the labor market and link both of these to the economic development strategy which among others includes diversifying and transforming the economy, attracting foreign investment and ensuring a better strategic fit with citizen involvement and empowerment. It further aims to deal with shortcomings in labor market information, ensure economies of scale with regard to complex analytical work such as labor market supply and demand forecasting, and initiate activities that cannot be performed in any of the subsystems, but which are critical for the HRDS in the country. Motlanthe also noted that the HRDS spans several domains including education, labor market, industry and society noting that the problems that are intrinsic to these domains cannot be reduced to one institution or policies of one government department or institution. "They impact on the collective ensemble of institutions in the system and relate to a cross sectored mix of government policies, private sector initiatives, higher education and other academic institutions as well as the broader society," he said. Government has established the Human Resource Development Council with a view to supporting the HRDS. The council is a multi-sector, multistakeholder and expert-led advisory group which provides an environment promoting optimal participation of all stakeholders in the planning, stewardship, and monitoring and evaluation of human resource development activities in the country.

Human Development and Export: Export activities are a major source of economic growth and are considered important both at the national level and for individual businesses. Moreover, in the case of SMEs, they gain particular relevance, exporting being the most common foreign market entry mode for these firms. As a result of the intensifying globalization of the world's economies (Morgan and Katsikeas, 1997) as well as the focus on improving national deficits (Katsikeas et al. 1996) international business involvement is becoming particularly relevant both in terms of national prosperity and for individual organizations.

According to Gylfason (1999) exports are the mainstay of around a fifth or more of the world's population. Moreover, they might be a major source of economic growth, both directly because exports are part of production and indirectly as exports facilitate imports of goods, services and capital, hence new ideas, knowledge and technology become available. At the macro level, the engagement of more companies in export activities is considered as being an effective way for coping with trade deficit problems (Morgan and Katsikeas, 1997) as well as a mean of enhancing the accumulation of foreign exchange, of improving the level of employment, of increasing national productivity and of driving economic growth (Czinkota, 1994) whereas at the micro level exporting can provide individual businesses with opportunities to grow, increase profits and stabilize demand (Ramaseshan \& Soutar, 1996) and to improve the utilization of production capacity, to develop superior management capabilities, to enhance innovation in product and process, and to strengthen financial performance (Terpstra \& Sarathy, 1997).

\section{Literature Review}

Kuznets noble prize winner in economy in 1971, the concept of capital which only includes physical and goods capital is a deficient and insufficient concept. Therefore, we should consider both human and physical capital. Concerning that he says, the human capital of a developed country is not its tools and equipments but is the knowledge gained from experiments and job skill of its people to use this knowledge. He believed that investment in training is an important source of creating human capital like enabling the workforce and developing technical knowledge and regarded human resource as an 
important factor in economic development of a country (Sobhani, 1992). Furthermore, Shultzer, the father of human capital theory, believed that the role of quality improvement which is achieved through investments in human capital and is a determinant of growth in traditional analyses of factors effecting economic growth is forgotten. Then they added human capital to the pattern as a production factor and estimated again for the same countries. In which they concluded that the human capital variable is meaningful in all cases. In order to study the role of human capital in economic growth of Japan by using the data collected from 1970-1991, evaluated the role of human capital in GNP and economic growth. The results of his research show that the spending in training and the workforce's years of schooling as two indices of human capital had positive and meaningful effects on Japan's economic growth.

\section{Methodology}

Early neoclassical growth models did not consider education as an input to production. It was only in the 1960s when education began to be seen as one of the variables that account for the unexplained residual in growth accounting exercises. This research has descriptive correlation features upon to applied purposes and degree of supervision is the kind of field research. According to exploration and data which have been obtained in department of Physical education including the branches of Mazandaran, the researchers noticed that between 500 members as participant in this research employee which are working in different organizations at the end of research about 100 members had given positive answers to this research, but at the final level of accomplishment, the numbers of participant decreased to 86 members for data collection, some questionnaire which are confirmed by researchers associations from valid sources, were used. This study is a descriptive-correlative for analyzing gathered data. The researchers used some available sources particularly mathematic solutions for gaining logical outcomes.

Table 1: Correlation Coefficients

\begin{tabular}{lcc}
\hline Mangers gratitude for hard working employees & r & $\begin{array}{c}\text { Significant } \\
\text { level }\end{array}$ \\
\hline Having explanation of vocational tasks & 0.214 & 0.001 \\
Employees participation for decision making & 0.259 & 0.000 \\
Sincerely relations between managers and employees & 0.198 & 0.002 \\
Managers attention to final outcomes & 0.345 & 0.000 \\
Freedom and independence for doing tasks & 0.164 & 0.003 \\
Identifying employees evaluation criteria's & 0.264 & 0.012 \\
Supervising affairs upon to skills & 0.187 & 0.020 \\
Suggestions and complaints system & 0.452 & 0.000 \\
Having standards of work & 0.147 & 0.004 \\
Managerial support for successful accomplishment of affairs & 0.621 & 0.000 \\
Statement & 0.354 & 0.005 \\
Believe to work & 0.412 & 0.013 \\
Level of Knowledge and skills & 0.542 & 0.003 \\
Using incentive and punishment system & 0.346 & 0.005 \\
Experience and enough talent & 0.212 & 0.000 \\
Training human resources & 0.452 & 0.015 \\
Focusing managers on employees weaknesses & 0.451 & 0.004 \\
Salary equivalence with pre background & 0.345 & 0.000 \\
Performing common meeting about working affairs & 0.132 & 0.001 \\
Having job security & 0.721 & 0.000 \\
Continuing employees evaluation & 0.401 & 0.021 \\
\hline
\end{tabular}

Production Function Cobb-Douglas is very simple and very common form of production function gives the following form (Farjadi, 1992):

$$
Q=A K^{\alpha} L^{\beta}
$$

That $\mathrm{A}$ is coefficient Technology, $\mathrm{K}$ physical capital, $\mathrm{L}$ force work and $\beta, \alpha$ Demonstrate to the capital elasticity of production and work. $\beta+\alpha$ is represent homogeneous, because:

$$
F(\lambda K, \lambda L)=A(\lambda L)^{\alpha}(\lambda L)^{\beta}+\lambda^{\alpha+\beta} A K^{\alpha} L^{\beta}=\lambda^{\alpha+\beta} Q
$$


So when the function is $\alpha+\beta=1$ Cobb-Douglas shows constant returns to scale. Per capita, which is written as $q+A K^{\alpha}$ ?

$$
\begin{gathered}
\frac{\partial Q}{\partial K}=a A K^{\alpha-1}=a \frac{Q}{K} \\
\frac{\partial Q}{\partial L}=\beta A K^{\alpha} L^{\beta-1}=\beta \frac{Q}{L}
\end{gathered}
$$

Thus, $\beta, \alpha$ demonstrate to the capital elasticity of production and work. The following table shows the status indicators of value added, employment and labor productivity in economic sectors in the years 2000-2007, which is given for comparison below:

Table 1: Status indicators of value added, employment and labor productivity in economic sectors in the years 2000-2007

\begin{tabular}{ccccc}
\hline $\begin{array}{c}\text { Total } \\
\text { economic }\end{array}$ & $\begin{array}{c}\text { Industry and } \\
\text { mining sector }\end{array}$ & $\begin{array}{c}\text { Oil and } \\
\text { Gas sector }\end{array}$ & $\begin{array}{c}\text { Agricultur } \\
\text { al sector }\end{array}$ & year \\
\hline 6.4 & 11.3 & 3 & 4.9 & \%Value added growth \\
4 & 3.6 & 1.2 & 1.5 & \%Employment growth \\
100 & 16.6 & 0.6 & 15.5 & $\begin{array}{c}\text { The average employment } \\
\text { share of this part of total } \\
\text { \%Labor productivity growth }\end{array}$ \\
2.3 & 7.5 & 1.7 & 3.4 & \\
\hline
\end{tabular}

\section{Results}

In this section, the total workforce employed in the economy, we have divided into two sections with higher education and workforce lacking, and the production per capita has also used the whole economy of production. Here, we wanted to show the impact on human resources development specialist entire economy, the resulting equation is estimated:

$$
\begin{gathered}
\log Y=0.49 \log K_{Y}+0.37 \log _{Y}-0.12 E X_{Y}+0.18 D U 79+0.26 D U 88 \\
\begin{array}{ccc}
(1.13) & (8.124) \quad(-10.04) \\
\text { F }=112 & \text { D.W }=2.12 \quad{ }^{-2}=0.94
\end{array}
\end{gathered}
$$

Here, the coefficient of human capital, i.e. highly educated employees, which is 0.37 suggests a strong and positive impact on economic growth force, and shows a percentage increase in the number of employees with higher education studies can increase 0.37 percent economic growth. Coefficient of physical capital is 0.49 , but the associated $t$ statistics to show that this coefficient is acceptable with 97 percent probability.

\section{Conclusion}

The purpose of this study has been to investigate human resource of employee productivity in the Iran context. The results of this study strongly support the research question, as there is significant relation of employee productivity with human resource including selection, employee benefits, compensation, training and staffing practices. Thus, banks create a more competent and committed workforce, which in turn provides a source of sustainable competitive advantage.

Economists have tries in many different ways to evaluate investment costs and benefits in human resources. After all, ARDL was used regarding the purpose of this research i.e. studying the role of human capital in GNP to measure the change in dependant variable after changing a variable by one unit. The results of these estimations about human capital show this important point that the human capital factor is a stable and meaningful factor with a positive coefficient in all equations, which shows the positive effect of human capital on output. Coefficient of workforce in this system implies the labor-intensive production i.e. products are less capital-intensive than human capital. Consequently, one of the main and crucial factors in inefficiency is the improper utilization of productive capacity in which we should also seek technologic changelessness in the country's production. Training is an important factor in human resources productivity improvement in producing goods and services, which causes growth. We should also mention that we should also pay attention to training during work, vocational and technical trainings 
and public advanced trainings; the last one is only limited to staff in Iran and has not been put into action yet. However, the findings should be interpreted carefully, as there are number of limitations which also represent opportunities for future research, unmeasured exogenous variables may affect the relationships we studied.

\section{References}

Autor, D., Levy, F., Richard, J. \& Murnane, F. (2003). The Skill Content of Recent Technological Change: An Empirical Investigation. Quarterly Journal of Economics, 118(4), 1279-1333.

Bloom, N., Sadun, R. \& Van Reenen, J. (2009). The Organization of Firms across Countries. Centre for Economic Performance Discussion, Paper 937.

Czinkota, M, R. (1994). Export Promotion and Competitiveness: The case of small- and Mid-Sized U.S. Firms, in International Marketing Strategy: Environmental Assessment and Entry Strategies, Michael

Farjadi, G. (1992). Introduction of Theories of Growth and Development. Alborz Publication (in Persian).

Garicano, L. (2000). Hierarchies and the Organization of Knowledge in Production. Journal of Political Economy, 108(5), 874-904.

Gylfason, T. (1999). Exports, Inflation, and Growth. World Development, 1031-1057.

Katsikeas, C. S., Piercy, N. F. \& Ioannidis, C. (1996). Determinants of Export Performance in a European Context. European Journal of Marketing, 30(6), 6-35.

Kuznets, S. (1971). Economic Growth of Nations: Total Output and Production Structure. Cambridge, Mass.: Harvard University Press.

Marks M. L. (1997). Let's Make a Deal. HR Magazine, 42.

Morgan, R. E., \& Katsikeas, C. S. (1997). Obstacles to Export Initiation and Expansion Omega. International Journal of Management Science, 25, 677-690.

Ramaseshan, B.,\& Soutar, G. N. (1996). Combined Effects of Incentives and Barriers on Firms' Export Decisions. International Business Review, 5(1).

Schmidt, A. J. (2003). Making mergers work, the strategic importance of people. Towers Perrin and Society for Human Resource Management Publication.

Selden, L.,\& Colvin, G. (2003). M\&A needn't be a loser's game. Harvard Business Review, 81(6), 70-79.

Sobhani, H. (1992). Return on training investment. Journal of Economic Research, 1(2).

Terpstra, V.,\& Sarathy, R. (1997). International Marketing, Forth Worth, TX: The Dryden Press.

Van Reenen, J.,\& Caroli, E. (2001). Skill biased organizational change? Evidence from British and French establishments. Quarterly journal of economics, 171 (4), 1449-1492 